\title{
School Resource Officers and Exclusionary Discipline in U.S. High Schools: A Systematic Review and Meta-analysis
}

\author{
Benjamin W. Fisher $^{1}$ (D) Emily A. Hennessy ${ }^{1}$
}

Received: 28 May 2015/Accepted: 28 May 2015/Published online: 4 June 2015

(C) Springer International Publishing 2015

\begin{abstract}
Over the past few decades, schools in the U.S. have increasingly relied on school resource officers (SROs) to provide safety and order within school settings. In spite of the intuitive appeal that SROs might offer for making schools safer, critics suggest that there may be unintended negative consequences to this trend, including an increase in exclusionary discipline (i.e., suspensions and expulsions) of students in schools with SROs. This study presents a synthesis of the existing quasi-experimental literature examining the relationship between the presence of SROs and exclusionary discipline in U.S. high schools. Following a systematic literature search, random effects meta-analysis was used to summarize ten effect sizes from seven reports. One meta-analytic model with seven effect sizes achieved statistical significance, yielding a mean rate ratio of $1.21,95 \% \mathrm{CI}(1.04,1.40)$, indicating that the presence of SROs in high schools was associated with higher rates of exclusionary discipline. A second metaanalytic model with three effect sizes indicated no statistically significant relationship between SRO presence and rates of exclusionary discipline [rate ratio $=1.54,95 \% \mathrm{CI}$ $(0.78,3.06)]$. There were high levels of heterogeneity in both models, indicating that unmeasured moderating variables would likely explain some of the variance. Implications for research are discussed.
\end{abstract}

Keywords School resource officers - Exclusionary discipline $\cdot$ Suspensions $\cdot$ Expulsions $\cdot$ Meta-analysis

Benjamin W. Fisher

benjamin.w.fisher@vanderbilt.edu

1 Vanderbilt University, Peabody \#90, 230 Appleton Place, Nashville, TN 37203, USA

\section{Introduction}

Schools are one of the key locations of development for adolescents; they spend nearly half of the days in a year at school, where they receive academic training, socialize with peers and adults, and learn skills that will help them become successful adults. Finding ways to maximize adolescents' academic and non-academic learning in school is therefore a critical undertaking for ensuring the healthy development of individual adolescents as well as that of society more generally. Unfortunately, exclusionary discipline practices such as out-of-school suspensions and expulsions hinder student learning. In the 2009-2010 school year, $83 \%$ of U.S. public high schools either expelled or suspended a student for at least 5 days with a total of over 400,000 of such punishments administered to students (Robers et al. 2013). Students who receive such discipline miss instructional time, leading them to fall further behind in classes and score lower on standardized tests (Arcia 2006; Kupchik 2010; Raffaele Mendez 2003; Suh and Suh 2007). Furthermore, exclusionary discipline has not been shown to act as an effective deterrent of future misbehavior. Adolescents who have been suspended are at greater risk for negative behavioral outcomes (Tobin et al. 1996), including increased contact with the juvenile justice system (Christle et al. 2005; Fabelo et al. 2011). The use of exclusionary discipline is also associated with poorer outcomes for schools more generally. Schools that use more exclusionary discipline fare worse on standardized tests (Raffaele Mendez et al. 2002; Rausch et al. 2004) and have higher dropout and lower graduation rates (Christle et al. 2007). Highly punitive environments have negative academic consequences even for students who are not direct recipients of discipline (Perry and Morris 2014). These negative outcomes are one reason that the U.S. Department 
of Education (2014) urged schools to limit their use of zero-tolerance discipline policies.

Concurrent with national discussions about exclusionary discipline, federally funded efforts have attempted to make schools safer in ways that may also affect school discipline. In response to the school shooting at Sandy Hook Elementary School in Newtown, Connecticut in 2012, President Obama unveiled a federal strategy devoted to making America's schools safer, within which he pledged funding for hundreds of school resource officers (SROs) around the country (The White House 2013). SROs-sworn police officers assigned to a particular school or school district who are responsible for maintaining school safety (Canady et al. 2012)_are not an uncommon presence in schools; estimates indicate that between 58 and $70 \%$ of schools had some sort of police or security personnel in the 2011-2012 school year (Robers et al. 2014). However, some critics have suggested that rather than making schools safer, SROs may have iatrogenic effects, including increasing schools' rates of exclusionary discipline (e.g., Hirschfield 2008). If this proliferation of SROs is associated with increased discipline rates, this effect could potentially lead to further negative outcomes for both adolescents and schools.

Although SROs were implemented to address physical threats to school safety, they have become increasingly involved in matters internal to the school, particularly adolescent problem behaviors. For instance, Finn et al. (2005a) found that SROs and zero-tolerance policies functioned as mutually reinforcing agents of discipline within one school district. Similarly, in an ethnography of school discipline practices and processes, including the involvement of SROs, Kupchik (2010) found that SROs have become an important part of school discipline processes, and as a result of this involvement the severity of punishments given has increased. For example, unruly adolescent behavior might be considered "horseplay" by teachers and administrators, resulting in a visit to the principal's office or detention. Alternatively, an SRO might view the same behaviors as "disorderly conduct," potentially resulting in harsher school-based punishment and even involvement with the juvenile justice system. In fact, some scholars have suggested that this punishment of highly interpretable behaviors may be one mechanism by which SROs increase discipline rates ( $\mathrm{Na}$ and Gottfredson 2011; Theriot 2009). Because implementing SROs into schools randomly has been unfeasible or unethical, there have been no randomized control trials to date examining any effects of SROs. However, because SROs may be linked with adolescents' success in school, it is critical that schools and policymakers make decisions about SROs using the best available evidence. Therefore, the current study synthesizes extant literature on the relationship between the presence of SROs in high schools and overall rates of exclusionary discipline. Given the current state of this topic as a burgeoning field of research, this study will examine the relationship between the presence of SROs and rates of exclusionary discipline rather than attempting to draw overall conclusions about whether SROs are effective in making schools safer. If introducing SROs into schools results in higher rates of exclusionary discipline, then future work should attempt to uncover the mechanisms by which this occurs.

\section{Conflicting Theoretical Frameworks}

Existing theoretical frameworks are in tension as to how SROs should be expected to affect exclusionary discipline. Routine activity theory suggests that victimization occurs when there is a confluence in time and space of three factors: a suitable target, a motivated offender, and a lack of capable guardians (Cohen and Felson 1979). In schools, SROs may function as guardians in spaces where victimization may occur in the absence of guardianship (e.g. hallways or cafeterias). This sense of guardianship could decrease victimization and other related problematic behaviors, which in turn could reduce rates of exclusionary discipline. The routine activity framework is consistent with other crime control approaches that argue that the more surveillance and guardianship there is in a school, the more likely it is that behaviors that merit exclusionary discipline will be either prevented or detected and dealt with appropriately, thereby discouraging such behaviors in the future (e.g., Hirschi 2002; Hirschi and Gottfredson 2003).

Alternatively, criminalization theories suggest that the presence of SROs may actually lead to an increase in the rate of exclusionary discipline. They suggest that schools mirror macro-level sociological trends that have become increasingly exclusionary and punitive (Hirschfield 2008; Kupchik and Monahan 2006). One way this may manifest itself is in the criminalization of adolescent behavior, where school discipline is delegated to SROs and police departments rather than being handled internally by school personnel. Adolescent misbehavior, then, becomes defined in legal terms rather than developmental ones; adolescents who misbehave are labeled as criminals and interface with the juvenile justice system when they might not have done so in the absence of SROs (Hirschfield 2008).

\section{Tension in the Roles of SROs}

SROs represent one model of school security personnel that has garnered much praise in recent years. Of particular salience for policymakers is that SROs are intended to act as a safeguard against high-profile mass shootings such as those at Columbine High School in 1999 or Sandy Hook 
Elementary School in 2012 (Borum et al. 2010; Pittaro 2007). This framework positions SROs as a gatekeeper between potential external threats and schools' interior learning environment. However, most SROs' duties include tasks and responsibilities that also involve functions within the school. Although the exact duties of SROs vary by location (Finn and McDevitt 2005; Kupchik 2010), the National Association of School Resource Officers-the largest professional organization of SROs-subscribes to a "triad model" where SROs' responsibilities fall into three domains: teaching, counseling, and law enforcement (Canady et al. 2012). The specific tasks of SROs in a given school are typically explicated via memoranda of understanding between local law enforcement agencies and schools, leading to considerable variability across locations in the daily roles and responsibilities of SROs (Covert 2007; Finn et al. 2005b). SROs may formally teach workshops or courses in school to increase adolescents' knowledge about the legal system, policing, and other related areas (e.g., Kupchik 2010; Rippetoe 2010). As counselors, SROs are expected to develop relationships with adolescents and appropriately address their needs, particularly around behavioral or legal issues. In their roles as law enforcers, SROs are supposed to maintain law and order in schools, with particular attention given to illegal behaviors. In fact, most SROs are only supposed to intervene in issues involving adolescents' problem behaviors when a law has been broken and refer them to other school personnel when the violation was only of a school-not legal—policy (Canady et al. 2012).

As noted by Kupchik (2010), there are tensions and ambiguities inherent to the SRO position. First, SROs are responsible to two different organizational structures (schools and police departments); some SROs have reported confusion about their place at the nexus of these two organizations, expressing a sense of ambiguity about the cultures and authority structures to which they belong (Dickmann 1999; Kupchik 2010). For instance, SROs have been trained and socialized in the culture of police departments-a culture that is not always compatible and sometimes at odds with the goals of a school. Criminalization theories would suggest that SROs' responsibility to police departments leads them to view problematic behaviors as crimes, whereas school personnel are trained to view them as obstacles to learning or developmental challenges. These differences in the ways that the two different authority structures perceive and address problematic behaviors leave SROs in tension between the two sides. Perhaps these differences are why SROs and their police department supervisors in one California county rated themselves as more proficient in their law enforcement duties than did school administrators (Murray 2003); proficiency might mean one thing to police and another to school administrators. ${ }^{1}$ The intersection of these two cultures has led to difficulties and tensions regarding how SROs interact with adolescents, particularly in regard to discipline.

A second tension that SROs experience is between their roles as law enforcers and as counselors (Kupchik 2010). As law enforcers, SROs are primarily expected to guard against external threats, but also to monitor illegal behaviors within the school (Canady et al. 2012; Covert 2007; Finn et al. 2005b). As counselors, SROs should make themselves available to assist adolescents with behavioral and legal issues and to offer advice about a wide range of topics (Finn et al. 2005b; Kupchik 2010). However, these roles may produce conflict for the SRO if adolescents share information with an SRO that implicates themselves, a friend or family member in an illegal activity (see, for example, Mulqueen 1999). Adolescents might expect a counselor to help them identify skills or strategies to address the presenting issue; however, because SROs have received most of their formal training as law enforcers (and not counselors), they may be much more likely to take legal action against the offending individual. So, where a adolescent might have hoped to receive counseling about a problem (such as drug use or gang involvement), the adolescent might end up interfacing with the justice system because of the SRO's role as a law enforcer, consistent with criminalization theories. This is a tension inherent in the job description of SROs and one that is likely dealt with differently across schools.

These tensions that SROs experience leave them in a difficult position. When SROs observe adolescents' problem behaviors, they must make a choice about whether or not to intervene. If the behavior is illegal, the choice is relatively straightforward; SROs are responsible for dealing with any illegal actions in school. If the behavior is not illegal, but violates school rules, SROs may feel it appropriate to intervene in their role as a teacher or counselor, even if law enforcement is not needed. Should they choose not to intervene in situations such as these, they might communicate that they are willing to tolerate rule-breaking behavior and thereby contribute to a sense of disorder at the school; therefore, they may be compelled to address these situations directly. However, because of their years of training and experience as law enforcers and status as sworn police officers, they may be especially quick to identify behaviors that could be categorized as illegal, potentially leading to more serious discipline for adolescents than if the SROs had never been involved (Hirschfield 2008; Hirschfield and Celinska 2011; Kupchik and

\footnotetext{
${ }^{1}$ It is noteworthy, however, that many school administrators have a highly favorable view of SROs and believe they contribute meaningfully to maintaining school safety (e.g., May et al. 2004).
} 
Monahan 2006), particularly with vaguely defined offenses that are subject to interpretation such as disorderly conduct. Both ethnographic (Kupchik 2010) and large-scale quantitative studies (Na and Gottfredson 2011; Theriot 2009) have found this effect: schools with SROs tend to be more severe in their punishment of misbehavior that could be considered open for interpretation. Although the exact reasons this may take place are unclear, it suggests that the tension inherent in SROs' job descriptions may be associated with schools' overall rates of exclusionary discipline.

\section{The Current Study}

Systematic reviews and meta-analyses are useful techniques for summarizing existing research on a given topic; such an undertaking is particularly relevant for SROs because they are costly to taxpayers and any potential effects of SROs-positive or negative-have implications for researchers, policymakers, and practitioners. To date, we are aware of one related systematic review (Petrosino et al. 2012) examining the relationship between school police and various adolescent academic and behavioral outcomes (e.g., academic achievement, fear at school), but it includes other types of law enforcement personnel besides SROs, does not explicitly address exclusionary discipline, and provides no quantitative synthesis of results. We are unaware of any meta-analyses that have examined student- or school-level outcomes associated with the presence of SROs. Therefore, the current study seeks to examine the relationship between SROs and exclusionary discipline by collecting and synthesizing prior research that has measured this relationship. Although the literature around the implementation of SROs is still growing, a meta-analysis at this stage could highlight the most important next steps to be addressed with primary literature. This is particularly relevant given that SROs are an expensive school-level intervention that lack rigorous experimental data about their effectiveness. Therefore, a meta-analysis can maximize use of the existing data to demonstrate strengths and gaps (Rosenthal and DiMattateo 2001) and provide relevant information for those interested in planning new studies (Borenstein et al. 2009). Indeed, one primary advantage to the synthesis of effect sizes in addition to a narrative review is that in a meta-analysis, the studies can first be weighted for their precision and then combined. By aggregating effect sizes across studies in this way, even if the aggregation only includes two studies, we increase validity and avoid leaving the reader to a vote count where studies are assessed solely by their individual P-values (Borenstein et al. 2009; Rosenthal and DiMattateo 2001; Valentine et al. 2010). Additionally, because individual studies often have low statistical power to reject the null hypothesis, meta-analyses often give more power to detect effects than single studies (Borenstein et al. 2009). Thus, if appropriate statistical methods are used, the metaanalysis can give a clearer picture of the impact of an intervention on outcomes of interest. As such, the research question for this study is: What is the association between the presence of SROs in U.S. high schools and schools' rates of exclusionary discipline? To answer this question, we conducted a systematic literature review and metaanalysis of existing primary research reports that measured the relationship between the presence of SROs and rates of exclusionary discipline.

\section{Method}

\section{Eligibility Criteria}

Reports had to meet several criteria to be included in this meta-analysis. First, the reports had to include data from high schools (i.e., grades 9 through 12); any reports that included schools where other grades were combined with high school were also included. Reports that collected aggregated district- or state-wide data from high schools were eligible for inclusion. Second, there had to be clear evidence that at least one SRO (not a non-SRO police officer or private security guard) was present at the school. The models of involvement of non-SRO security personnel in schools are often quite different from those of SROs (see, for example, Brady et al. 2007). Third, the report had to provide information for analytical comparison. This could include either (a) at least one comparison school that did not have an SRO; or (b) disciplinary incident report data about a school before and after it implemented an SRO. Fourth, reports needed to include data about rates of school-based disciplinary incidents. Three pieces of information are necessary to calculate rates of incidents: the number of incidents, the number of students in the school, and the time span over which the incident data were collected. Reports that did not provide sufficient information about any of these three variables were excluded unless we could find the information by contacting the author or searching online using publicly available school or district data.

\section{Data Sources and Search Process}

We used several sources to locate reports that might be eligible for inclusion in this meta-analysis with the goal of casting a wide net that might capture any study that focused on SROs. To this end, we searched the following electronic databases (current as of June 15, 2014): ERIC, IBSS, PAIS 
International, ProQuest Criminal Justice, ProQuest Education Journals, ProQuest Psychology Journals, ProQuest Social Science Journals, PsycARTICLES, PsycINFO, Social Services Abstracts, Sociological Abstracts, ProQuest Dissertations \& Theses: UK \& Ireland, and ProQuest Dissertations \& Theses. The search terms used across all databases were: TI, AB ("school resource officer" OR "school resource officers" OR "resource officer" OR "resource officers" OR SRO OR SROs OR SRO's). Additionally, we reviewed references and searched for subsequent citations of all eligible reports, hand-searched all past issues of the Journal of School Violence, and consulted with multiple experts familiar with research on SROs. We included unpublished literature in our search because we sought to guard this meta-analysis against publication bias (Rosenthal 1979), a problem that still appears in the social sciences literature today (Polanin et al. 2015). Unfortunately, whether a report is published is not necessarily a reflection of study quality. There is a history of publication bias across many disciplines where even well-conducted studies are not submitted for publication (Cooper et al. 1997; Dickersin 1997) or do not make it through the review process because of null or negative outcomes (Dickersin 1997; Scherer et al. 2007). Therefore, in this synthesis, we sought to reduce the potential of publication bias by searching for both published and unpublished studies.

\section{Study Selection, Coding, and Variables}

After performing this initial search, the first author filtered out any duplicates and reviewed the titles and abstracts for each report and excluded reports that were not topically related. Many reports excluded at this level came from medical or chemical reports where the abbreviation "SRO" was used, but not in reference to school resource officers. The first author then performed a full-text review of each remaining report and filtered out reports that did not meet our eligibility criteria outlined above. When data to calculate rates of exclusionary discipline were missing, we contacted authors in attempt to supplement the given information. After identifying all eligible studies, the two authors independently reviewed the studies and coded the study variables. Any disagreement was resolved by consensus, including reading and interpreting reports together and talking through the calculation of effect sizes.

\section{SRO Presence}

The key independent variable in this study is the presence of SROs in high schools. Because of the available information from research reports, schools with multiple SROs were analytically treated the same as schools with one
SRO. As mentioned previously, non-SRO police officers and other types of security guards are assumed to operate under a very different model from SROs, and thus schools that employed such personnel were not coded as having SROs.

\section{Exclusionary Discipline Rates}

Not all studies reported the same types of school-based exclusionary disciplinary rates and some reported multiple types. Therefore, we created a hierarchy of what disciplinary incidents to prioritize: (1) out-of-school suspensions; (2) expulsions; (3) arrests; and (4) reported crimes. This hierarchy emphasizes actual incidents of exclusionary school discipline (i.e., out-of-school suspensions and expulsions), but does not ignore incidents that likely merited disciplinary action, whether or not disciplinary action was ever taken (i.e., arrests and reported crimes). Although some scholars have conceptualized out-of-class discipline as exclusionary (e.g., Mitchell and Bradshaw 2013), the focus of this analysis is on out-of-school discipline. Some manifestations of in-school discipline (such as in-school suspensions) may include an element of academic engagement, particularly if adolescents receive tutoring or assistance with homework during their time of discipline, but out-of-school discipline precludes adolescents from having any sort of formal academic engagement at school and forces them to miss instructional time. Therefore, detentions and in-school suspensions were not included in this hierarchy because they do not exclude adolescents from school altogether (although they may miss classes), and their instantiation varies widely from school to school. Out-of-school suspensions, expulsions, and arrests represent disciplinary responses that are more likely to lead to missing instructional time and the associated negative consequences (e.g., Brown and Saks 1986; Clark and Linn 2003).

\section{School Variables}

Several school-level variables were collected for both the schools with and without SROs, the majority of which were used for descriptive purposes only. School level was measured as either high school only, or high school combined with other grades. The number of schools included in calculating the effect size was also coded as some effect sizes were based on data from a single school whereas others were based on pooled data from school districts or states.

School size (the total number of students), a variable needed to calculate the rate ratio, was coded based on the information provided in the reports. If school size was not provided, it was calculated based on other available 
statistics in the report or located online using the Common Core of Data website (U.S. Department of Education 2013). For reports that used a pre-post design, we coded school-level information differently at pretest and posttest if that information was reported. However, if it was only reported once, the same information was used for both time points (e.g., if the school size was only reported for one time point, we used that same value for both pretest and posttest calculations).

\section{Study Design and Report Variables}

Several study design variables were also coded. Two reportlevel variables were measured for each effect size: the type and year of publication. Four design variables were coded: the unit of SRO assignment (i.e., whether SROs were assigned to individual schools or districts); the study design (i.e., pre-post or comparison school); whether pretest differences were measured between SRO and comparison schools; and the significance of any pretest differences. Two variables relating to the reporting of in-school disciplinary incidents were measured: the source of incident data (i.e., official records, administrator reports, teacher reports, SRO reports, student reports), and the type of incidents reported (i.e., suspensions, expulsions, arrests, or reported crimes).

\section{Summary Measures}

The effect size used to synthesize results across studies in this meta-analysis is the rate ratio (Deeks et al. 2008). The rate ratio is useful to capture differences in rates of incidents (rather than counts of incidents) across two different groups. In this study, it was important to use rates rather than counts of exclusionary discipline to adjust for differences in school size. That is, there is a meaningful difference between two schools that administered 100 incidents of exclusionary discipline per year if one school has 300 students and the other has 1500. Rate ratios are calculated using the formula:

$\frac{\frac{E_{T}}{T_{T}}}{\frac{E_{C}}{T_{C}}}$

where $E_{T}=$ the number of events in the treatment group, $T_{T}=$ the amount of time in the treatment group, $E_{C}=$ the number of events in the control group, and $T_{C}=$ the amount of time in the control group. In this study, the events were spread out over people and time rather than just time. Therefore, rate ratios were calculated by dividing the number of incidents by both the number of students in the school and the length of time relative to a 9-month school year. For example, 100 events in a school with 1000 students over one school year would yield a $T$ value of .1, whereas 100 events in the same school during one half of a school year would yield a $T$ value of .2 . Some studies using a pre-post design did not report the number of students per school. To calculate the rate ratios for these schools, we assumed a constant school size, and the rate ratio calculation reduced to:

$\frac{E_{T}}{E_{C}}$.

To calculate the standard error (SE) of the logged rate ratio, we used the formula:

$\sqrt{\frac{1}{E_{T}}+\frac{1}{E_{C}}}$

where $E_{T}=$ the number of events in the treatment group and $E_{C}=$ the number of events in the control group. As recommended by Borenstein et al. (2009), prior to our analysis, all the outcome measures were logged to allow combination across reports, and then exponentiated after model estimation to ease interpretation.

\section{Analytic Strategies}

To estimate the relationship between SRO presence and overall rates of exclusionary discipline, separate random effects inverse variance weighted meta-analyses were conducted for each design type (i.e., pre-post and comparison school). We decided a priori to use random effects analysis because we could not justify the assumption that any potential effects of SROs would be the same across different contexts. In the pre-post design studies, we used the mean of pre-intervention rates of exclusionary discipline and compared them to rates calculated using the mean of all postintervention measurements, not including the year that the SROs were implemented (where available) in order to avoid any implementation effects in the post-SRO measurement. To further examine any heterogeneity, we calculated $Q, \tau^{2}$, and $I^{2}$ values for each model. Although we sought to avoid publication bias through our systematic search for both published and unpublished literature, we also used several meta-analysis techniques to assess the presence of publication bias in our included studies. We used three recommended techniques: we visually examined a funnel plot, conducted an Egger's regression test, and conducted a trim and fill analysis (Rothstein et al. 2005).

\section{Results}

\section{Study Selection and Characteristics}

The electronic database search yielded 923 reports. After removing trade journal and magazine articles and any duplicates, and reviewing the titles and abstracts of the remaining 
reports, we excluded 794 reports. We performed a full-text review of the remaining 129 reports and excluded 122 because they did not meet our predetermined eligibility criteria. No additional studies were added via our other search strategies; as such, the final sample consisted of seven reports. See Fig. 1 for more detailed information about the reasons for exclusion. Characteristics of the included reports are presented in Table 1. The seven eligible reports used for these metaanalyses were published between 1999 and 2010 as dissertations $(k=4)$, technical reports $(k=1)$ and peer-reviewed journal articles $(k=2)$ These seven studies provided us with ten unique study samples and their corresponding effect sizes, with the technical report contributing four separate effect sizes. All incident data were gathered from official school reports. Three of the effect sizes used a comparison school design and seven used a pre-post design. Schools without SROs ranged in size from 875 to 2350 students $(M=1478.52, S D=554.83)$ and schools with SROs ranged from 950 to 2350 students $(M=1510, S D=525.92)$. Three studies used pre-test matching based on school size only.

\section{Description of Studies}

\section{Barnes (2008)}

Barnes (2008) conducted a quasi-experimental study that examined the rates of reported crimes on school property before and after the implementation of SROs in high schools throughout North Carolina. The dependent variable in this study (rates of reported crimes) was gathered from administrative records and included the following crimes: assault, possession of a controlled substance, robbery, and weapon possession. According to North Carolina law, school personnel are required to report these crimes to law enforcement. A total of five waves of data were collected: one before SRO implementation (1995-1996) and four after SRO implementation (1996-1997 to 1999-2000). The baseline year had the lowest mean rate of reported crimes $(0.581$ per 100 students), although the differences between the baseline year and subsequent years were not statistically significant. Barnes (2008) also included a non-equivalent comparison group of schools that did not implement SROs and found no significant difference in the reported crime rates between the two groups of schools. Relative to the other included reports, this dissertation provided a large amount of data both in terms of the number of schools included and the number of measurement years. The multiple baseline years are particularly important because they provided additional information about the rate of exclusionary discipline prior to the implementation of SROs than only a single baseline year. Moreover, the analyses within this study controlled for baseline rates to draw more valid conclusions about the effect of implementing SROs.

Finn et al. (2005a): Large Established Site 3

The Department of Justice and the Office of Community Oriented Policing funded a national evaluation of SRO
Fig. 1 Flow chart of primary study inclusion

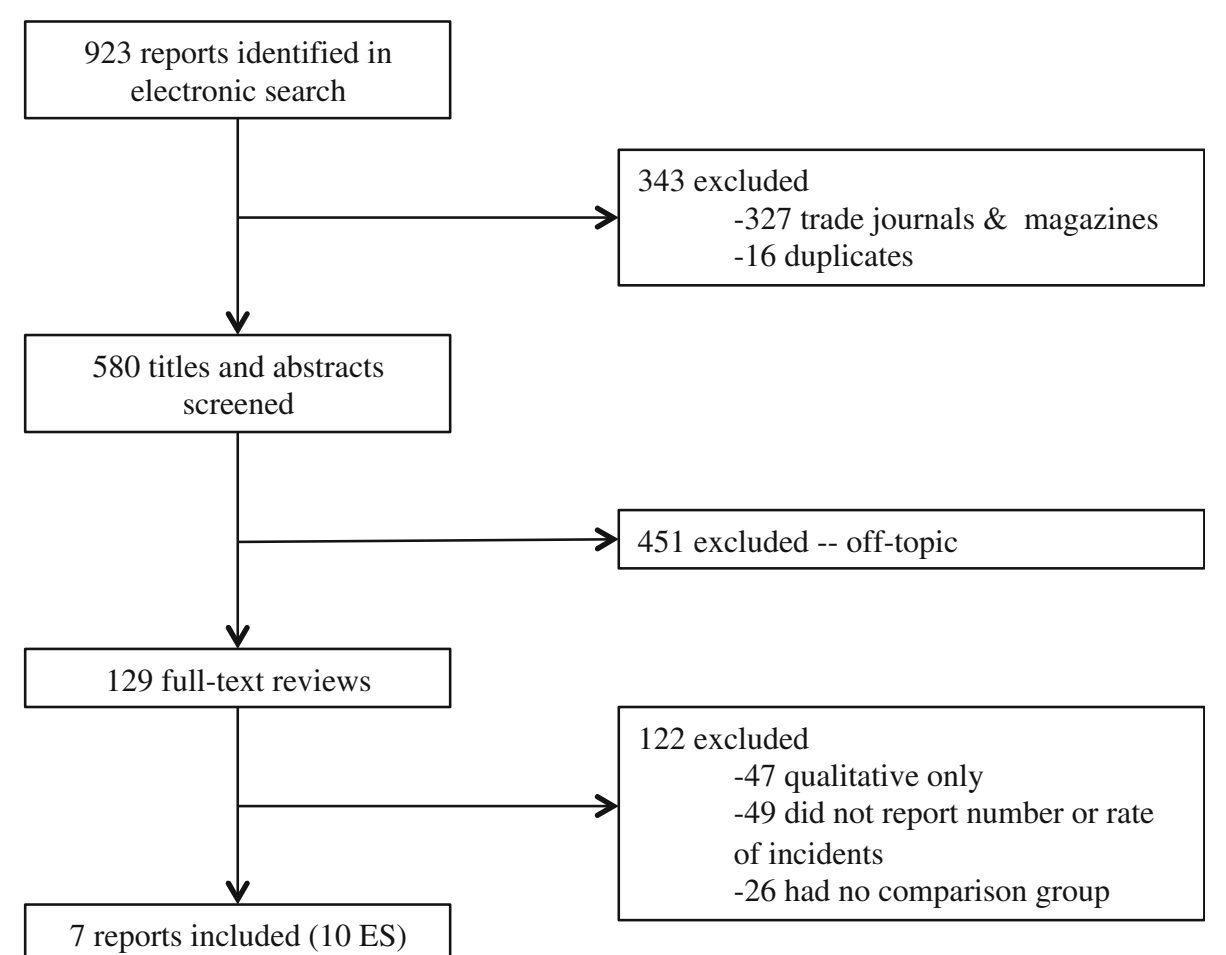




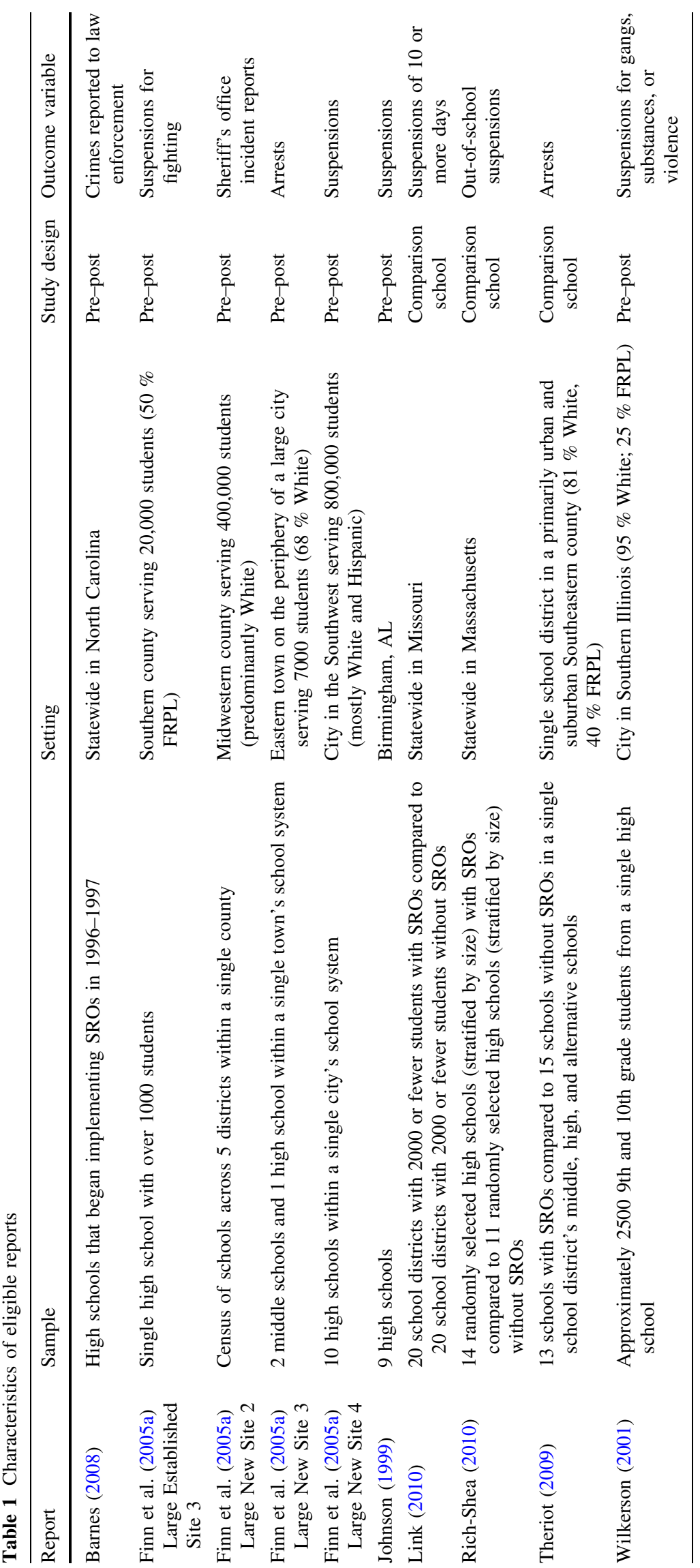


programs beginning in May 2000. Multiple technical reports were published from the findings of this evaluation, including a 448-page report by Finn et al. (2005a). The research team selected the 19 SRO programs based on multiple criteria, including a diversity of sizes of law enforcement agencies and longevity of SRO programs. More specifically, the 19 programs were categorized as large established programs, large new programs, small established programs, and small new programs. These case studies included extensive data collection of individual schools, school systems, and police departments, including interviews with multiple stakeholders, collection of administrative records, and surveys. Some of these case studies contained quantitative data that met the current review's eligibility criteria, but the authors made no attempt to quantitatively synthesize this information across the various sites.

A site called Large Established Site 3 was the first of four individual case studies eligible for this systematic review and meta-analysis. Large Established Site 3 is situated in a county with a population of roughly 100,000 in the South. Finn et al. (2005a) collected data on suspensions for fighting in one high school within this site over a 7-year span from 1994-1995 to 2000-2001, including 1 year of data before SRO implementation and 6 years of data after SRO implementation. There were 72 suspensions for fighting in 1994-1995-the year before SRO implementation; that number decreased to 48 when an SRO was implemented in the school in 1995-1996, and then declined even further in subsequent years to 32, 29, 28, 24, and 27 suspensions for fighting per year (although the authors did not conduct any formal significance tests). One potentially confounding variable is that a zero-tolerance policy for fighting was implemented in the same year as the SRO, thereby potentially obfuscating any effect that could be attributed solely to the SRO. In fact, Finn et al. (2005a) reported that the SRO and the zero-tolerance policy were mutually reinforcing and largely went hand-in-hand. The decrease in suspensions for fighting might also be attributable to regression to the mean; the SROs and zero-tolerance policies were implemented largely as a reaction to the rampant fighting in schools, suggesting that the amount of fighting may have decreased regardless of the changes.

\section{Finn et al. (2005a): Large New Site 2}

The second site from the Finn et al. (2005a) report eligible for inclusion-Large New Site 2-is in a county of 400,000 primarily White urban-dwelling people in the Midwest. Four waves of data were available, including 1 year before SRO implementation (1999) and 3 years after (2000-2002). The outcome data are comprised of reports to the sheriff's office from all schools in the district, including the following offenses: violent crime, property crime, domestic violence, sexual assaults, arson, bomb threats, drugs/alcohol, motor vehicle, status offenses, threats, warrant, non-criminal investigation, and other/unspecified. Although information about suspensions and expulsions was available, all of the data were collected after the implementation of SROs and therefore had no counterfactual for a comparison. In the last year before SRO implementation, there were 283 police reports filed with the sheriff's office; in the first year with SROs, this number increased to 374 , and then to 397 the following year. In the third year after SRO implementation, there had been 217 reports as of October 15, indicating a potential decline. School personnel suggested that the increase in reports to the sheriff's office in the first 2 years was due to increased reporting, not increased behavior problems.

\section{Finn et al. (2005a): Large New Site 3}

This site is situated on the east coast in a town with a diverse population of 45,000. SROs were implemented in the district's two middle schools and one high school in 1999-2000. Finn et al. (2005a) collected six waves of data on arrests at school for the district's high school, including two waves before SRO implementation and four waves after. In the 2 years before SRO implementation, there were 17 and 28 arrests. This number peaked at 35 in the year that SROs were implemented, and then declined afterwards to 31,12 , and 18 arrests per year in the final 3 years that data were available. There was a parallel trend in the number of police calls to the high school; the authors interpreted this as evidence that adolescents' behaviors in school improved and therefore the amount of discipline needed in the school decreased. A strength of the data from this particular site is the inclusion of multiple waves of data both before and after SRO implementation, allowing for stronger conclusions about baseline rates and post-intervention rates of exclusionary discipline than if only one wave of pre- or post-intervention data was provided.

\section{Finn et al. (2005a): Large New Site 4}

The final eligible site report from Finn et al. (2005a) is in a mid-sized city with a large Hispanic population in the southwest. SROs were implemented in the district's 30 middle and high schools in 1999. Finn et al. (2005a) tracked the total number of suspensions across 10 high schools in the district across four waves, including one wave before SRO implementation and three waves after. In the year before SRO implementation, there were a total of 2445 suspensions across the 10 high schools; this number dropped slightly to 2249 in the year that SROs were implemented and then rose in the following 2 years to 2763 
and 3230. Interestingly, whereas the total number of suspensions increased after SRO implementation, there was an overall decline in the number of long-term suspensions and reports of violence and weapons (although there was an increase in the reports of substance use). Taken together, these data may indicate that suspensions were increasingly relied on as punishment for relatively minor offenses at the same time that the incidence of more serious violent offenses dropped.

\section{Johnson (1999)}

In this study, SROs were implemented in the public school system in a southern city at the beginning of the 1995-1996 school year. Johnson (1999) collected three waves of data across nine high schools (one wave before SRO implementation and two waves after), although data collection for the third wave ended in November of 1996. The outcome measure used in this study was a summed total of suspensions for three types of offenses: minor Class I offenses (e.g., gambling, nonconformity to dress code, harassment or intimidation of other students), intermediate Class II offenses (e.g., fighting, larceny, leaving school grounds without permission), and major Class III offenses (e.g., arson, grand theft, possession of firearms or weapons). The total number of recorded offenses in the high schools in the year before SROs were implemented was 4049; this number dropped to 3760 in the year that SROs were implemented and was at 2154 in November of the final wave. The total number of suspensions for Class I and Class III offenses each increased from Wave 1 to Wave 2, and suspensions for Class II offenses decreased. Because the data from Wave 3 were incomplete, it is unclear whether the overall drop in the number of suspensions would have continued in the same direction.

\section{Link (2010)}

This study examined the relationship between the presence of SROs in Missouri school districts with 2000 or fewer students. Specifically, Link (2010) compared differences in the number of suspensions for 10 days or more between 20 districts with SROs and 20 districts without SROs in a single year. At the time of the study, the Missouri School Resource Officers Association reported that there were 20 total districts with a student population of 2000 or less that had SROs; all of these districts were included in the study. The comparison districts were selected randomly from a list of the remaining districts with a student population of 2000 or less. Link (2010) found no significant difference in the number of suspensions for 10 days or more between districts with SROs $(M=8.20, S D=13.13)$ and those without $(M=9.40, S D=14.10)$. This study was one of the few eligible for inclusion in this review that included a priori matching criteria for the schools in the sample. This allows for stronger conclusions to be made because it reduces the presence of potentially confounding school characteristics that may have introduced bias.

\section{Rich-Shea (2010)}

In this study, Rich-Shea (2010) examined the differences in suspension rates between high schools with and without SROs in Massachusetts across six waves of data. High schools were considered eligible for this study if they served grades 9-12, did not have their own police force, and were not a charter school, alternative school, vocational school, or other specialized school. After stratifying 180 eligible high schools in the state by size (small, medium, and large), 14 randomly selected public high schools with SROs were compared to 11 randomly selected high schools without SROs. This stratified random sampling in study helped to bolster the study's internal validity while still retaining a relatively large sample of schools. Out-of-school suspension rates were higher in schools with SROs across all six waves of the study, although rates in both groups declined markedly over the duration of the study. Interestingly, in-school suspensions decreased in a similar pattern among schools without SROs, but schools with SROs saw an increase in their rates of in-school suspension. When combining these two suspension types, Rich-Shea (2010) found that schools with SROs maintained a fairly steady rate of suspension whereas schools without SROs decreased their rate of suspension. RichShea (2010) suggested that schools with SROs may have begun to use in-school suspensions rather than out-of school suspensions, resulting in very little change in the overall rate of suspension, but a decline in out-of school suspensions.

\section{Theriot (2009)}

This quasi-experimental study examined the relationship between the presence of SROs and the rate of arrests at school. The study included data from 13 schools with SROs and 15 schools without SROs across a 3-year span (2003-2004 through 2005-2006). In an unadjusted negative binomial regression model, the presence of SROs predicted a significant increase in the rate of total arrests per 100 students $(M=11.5, S D=25.1$ in schools with SROs; $M=3.9, S D=6.9$ in schools without SROs). However, when including the percent of students with economic disadvantage as a covariate the presence of SROs was no longer a significant predictor of arrest rates. Theriot (2009) also disaggregated the total number of arrests into six categories: assault, weapon on school 
property, drugs, alcohol/public intoxication, disorderly conduct, and other charges. In unadjusted models, the presence of SROs was a significant predictor of higher arrest rates for disorderly conduct and other charges, and remained a significant predictor of higher arrest rates for disorderly conduct when controlling for the percent of students with economic disadvantage as well as the interaction between these two independent variables. Therefore, the increase in the overall arrest rate attributable to SROs may be driven largely by the increase in arrests for disorderly conduct.

\section{Wilkerson (2001)}

This study focused on the relationship between the presence of an SRO in a single high school in Illinois and the number of suspensions due to violence, gang activity, and substance use (including alcohol). To examine this relationship, Wilkerson (2001) used four waves of annual suspension data, including two years before SRO implementation and two after. Suspension data were collected for students who were in 9th grade in 1996-1997 and 10th grade in 1997-1998-before the SRO was implemented; this sample served as the control group. After the SRO was implemented in the beginning of the 1998-1999 school year, suspension data were collected for those students who were in 9th grade in 1998-1999 and 10th grade in 1999-2000; this sample served as the experimental group. In the control group, 88 suspensions were administered in the 2-year timeframe, representing $6.82 \%$ of the students. There was no significant difference in the experimental group; students in this group received 90 suspensions, including $7.32 \%$ of the students. In further analyses, Wilkerson (2001) found no effect of SROs on overall rates of suspensions for violence, but found that females were suspended due to violence significantly more after SRO implementation; there was no difference for males. There was no effect of SROs on suspensions due to gang activity, nor was there any gender effect. Similarly, there was no effect of SROs on overall or gender-specific suspensions due to substance/alcohol use. Although this study only included a single school, the study design eliminated any between-schools confounding variables, and the presence of any within-school confounding variables was likely only due to variation by year.

\section{Synthesis of Results}

To quantitatively synthesize the results of the eligible reports, separate random effects meta-analyses were conducted for effect sizes derived from studies using either a comparison school or pre-post design. Each of these designs has different underlying assumptions about the nature of the effect of SROs on exclusionary discipline and therefore this warrants separate analysis by design. Because of the small number of effect sizes in each study, we did not include any control variables in our analyses. Figure 2 displays the results for the comparison school meta-analysis $(k=3)$. This meta-analysis yielded a mean rate ratio of $1.54,95 \% \mathrm{CI}(0.78,3.06)$, a value not significantly different from the null effect. This indicates that in studies that used a comparison school design, the rate of school-based disciplinary incidents in schools with SROs was not significantly different from the rate in schools

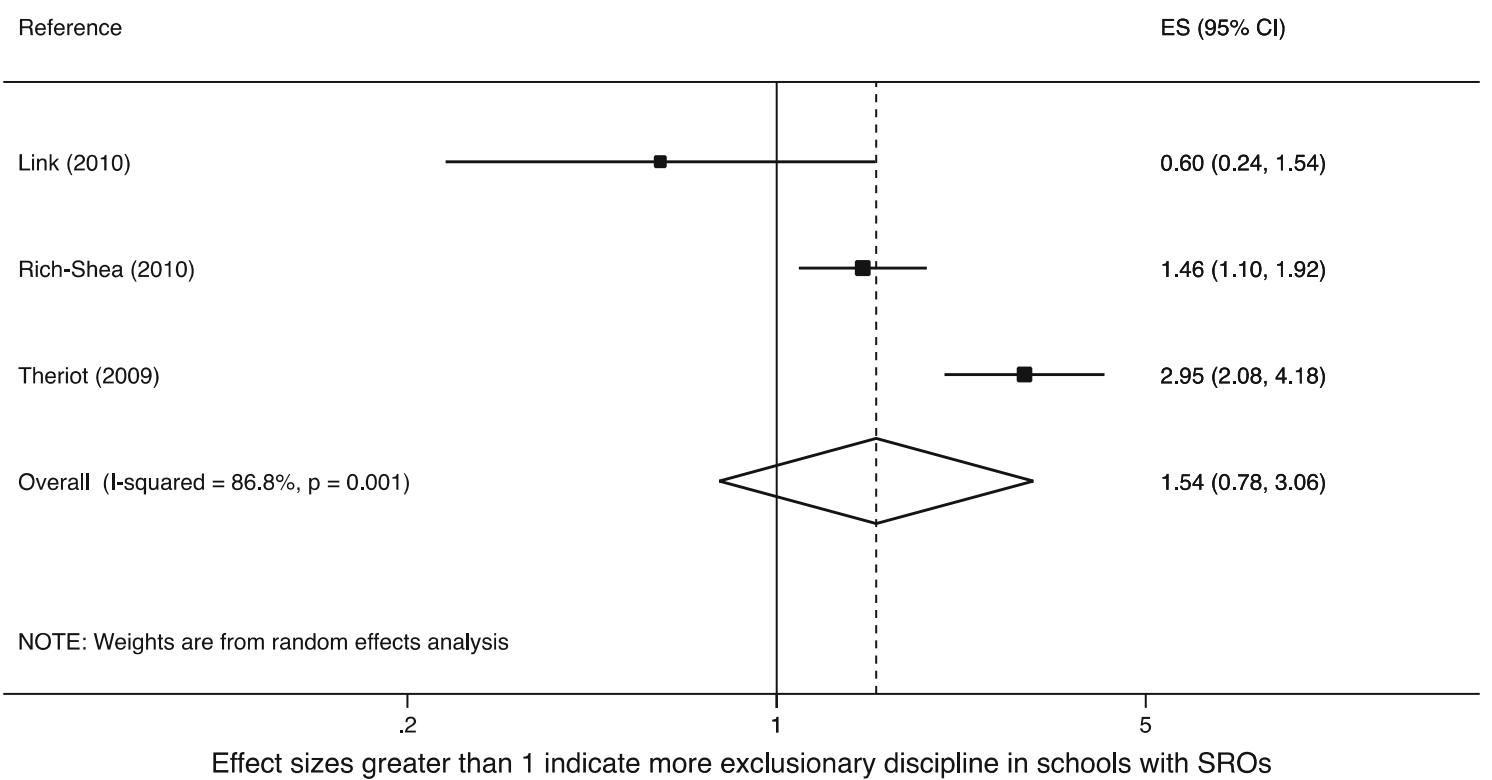

Fig. 2 Forest plot for meta-analysis of rate ratios of exclusionary discipline from studies using a comparison school design $(k=3)$ 


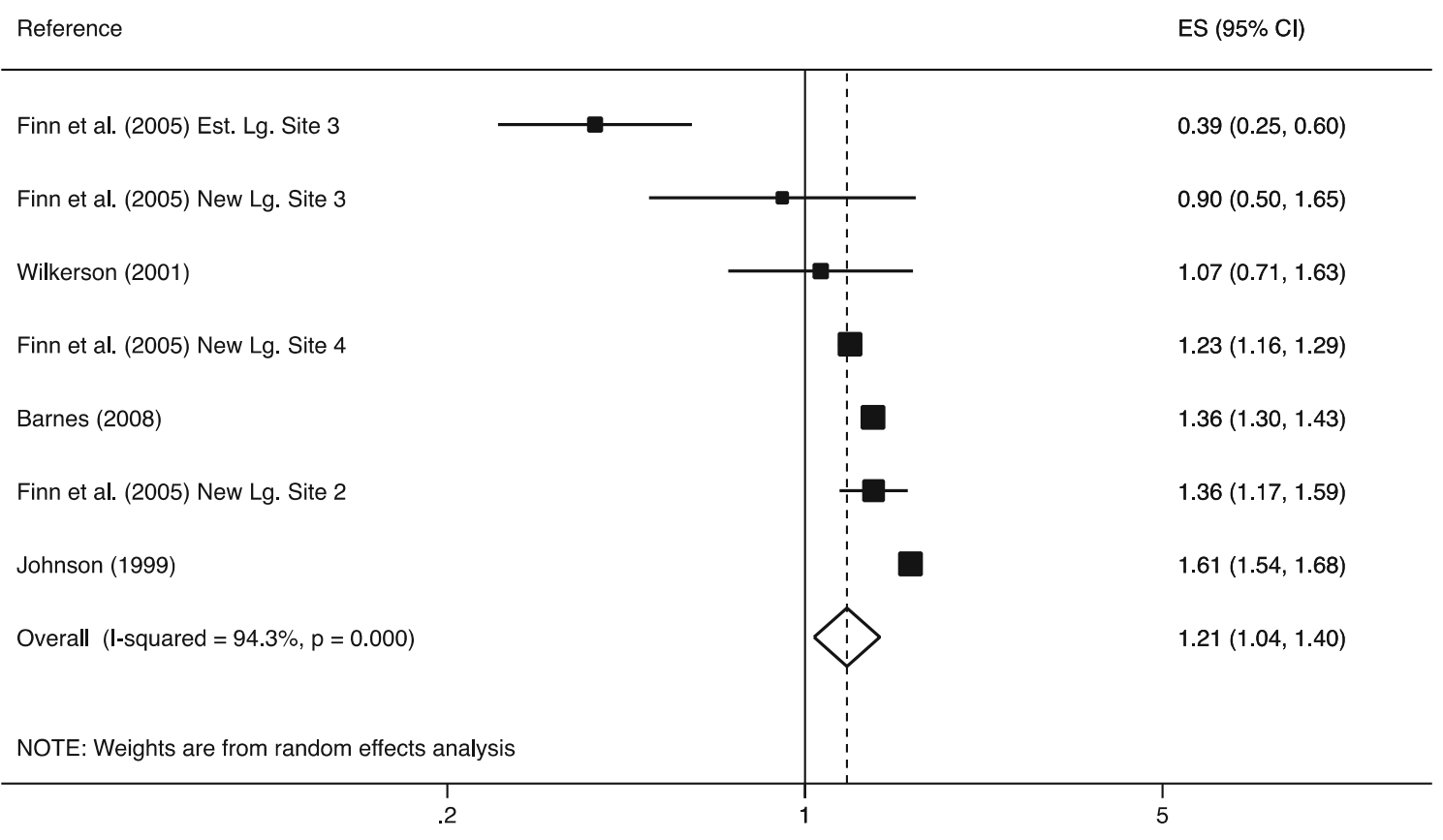

Effect sizes greater than 1 indicate more exclusionary discipline in schools with SROs

Fig. 3 Forest plot of meta-analysis of rate ratios of exclusionary discipline for studies using a pre-post design $(k=7)$

without SROs. There was a significant amount of heterogeneity in this model $(Q=15.14, p=.001)$, including a large amount of between-study heterogeneity $\left(\tau^{2}=0.29\right)$, indicating that including moderators in the model could provide a more precise estimate and explain within- and between-study heterogeneity. Moreover, an $I^{2}$ value of $86.8 \%$ indicates that most of the heterogeneity in this model is due to real heterogeneity, and not sampling error.

Figure 3 presents the pre-post design meta-analysis $(k=7)$, which yielded a statistically significant mean rate ratio effect size of $1.21,95 \% \mathrm{CI}(1.04,1.40)$. Schools with SROs had roughly $21 \%$ higher rates of school-based disciplinary incidents than they had before implementing SROs. In a school of 1500 students, this would be the difference between 180 and 218 incidents of exclusionary discipline in a single school year. In a 180-day school year, this is roughly equivalent to an extra student being excluded from school every week. The pre-post design metaanalysis had a significant amount of heterogeneity $(Q=104.47, p<.001)$ with almost all of it potentially explainable by moderators $\left(I^{2}=94.3 \%\right)$, and not by random sampling error. The large amount of observed heterogeneity may be due to the variety of outcome variables in the 7 eligible studies. As seen in Table 1, outcome variables in this model included suspensions, suspensions for fighting, suspensions for gangs, substances, or violence, incidents reported to the Sheriff's office, and crimes. The $\tau^{2}$ value of .03 suggests that this pre-post design model had less variability in the effect size parameters than the comparison school model (although the difference in these values was not directly tested), but that it still includes between-study heterogeneity.

\section{Publication Bias Analysis}

To test for publication bias in the studies using pre-post designs, we visually examined a funnel plot and conducted both Egger's test and a trim and fill analysis. Although it was difficult to gauge the presence of asymmetry from visual inspection of the funnel plot-as would be expected from the relatively small sample of reports-Egger's regression test was not statistically significant $(p=.209)$ and the trim and fill analysis added no new studies. The results of these tests indicate a lack of evidence supporting the presence of publication bias in this analysis.

\section{Discussion}

In recent years, there has been a rapid expansion of SROs into high schools across the country (Robers et al. 2014). Although SROs have been implemented to increase the safety of students and schools, there may be iatrogenic effects associated with their presence, including increased rates of exclusionary discipline (Hirschfield 2008; Kupchik 2010; Kupchik and Monahan 2006) that lead to negative impacts on students and schools (Balfanz et al. 2015; Christle et al. 2005, 2007; Perry and Morris 2014). The 
purpose of the current study was to examine the association between SRO presence and rates of exclusionary discipline in U.S. high schools by synthesizing extant empirical research. Using ten effect sizes from seven reports, we found that the pattern of results across the separate random effects meta-analyses provides evidence that-consistent with theories of criminalization-the presence of SROs in high schools is associated with higher levels of exclusionary discipline, although only one of the two models achieved statistical significance. The point estimate from the meta-analysis that achieved statistical significance $[1.21,95 \%$ CI $(1.04,1.40)]$ indicated that the presence of SROs was associated with the equivalent of approximately one additional exclusionary discipline incident per week in a school of 1500 students-certainly not a trivial amount. The second model largely followed this same pattern, although the point estimate was not significantly different from zero, perhaps because of a lack of power due to the small sample size $(k=3)$. Although we were unable to statistically compare the two models because of the different underlying assumptions in the study designs, the overall pattern of results is largely similar across the two models; the mean effect sizes have confidence intervals with a high degree of overlap, and both models show a significant heterogeneity that could potentially be modeled. Perhaps the largest difference between the two models is between the $\tau^{2}$ values. This is not entirely surprising as there were over twice as many effect sizes included in the pre-post design meta-analysis than in the comparison schools meta-analysis, and $\tau^{2}$ is dependent on sample size. The overall pattern of results suggests a consistency of results across design type that lends credence to the overall estimated rate ratio effect sizes.

There are multiple possible explanations for the significant relationship we found. First, it is possible that the presence of SROs increases the detection of or severity of response to problem behaviors even though the incidence of problem behaviors remains the same. This explanation implies that SROs have no actual impact on adolescent behaviors, but do increase the overall amount of exclusionary discipline. Such a phenomenon would be consistent with theories of criminalization that suggest SROs are a key mechanism in the trend towards excluding adolescents from school en route to the juvenile justice system (Hirschfield 2008; Kupchik and Monahan 2006). Alternatively, it may be that adolescents' problem behaviors decrease with the presence of SROs, but the detection and punishment of the remaining misbehavior has increased dramatically with SROs in the school. The reduction of problem behaviors is consistent with crime control theories (Hirschi 2002; Hirschi and Gottfredson 2003), but these theories do not directly address why discipline rates would still be high. Both of these explanations have some support in qualitative research; for instance, Kupchik (2010) found that in some cases the presence of SROs leads adolescents to receive more severe disciplinary consequences than they would have otherwise. A third explanation is that the presence of SROs leads to an increase in behavioral problems, which in turn are punished at the same rate-or a higher rate-than they would be without SROs. Such an explanation may be consistent with social disorganization theory (Sampson and Groves 1989; Shaw and McKay 1942), which suggests that social or physical disorder acts as a signal that disorderly behaviors are expected there. SROs are typically placed in large, urban schools that are often - at least anecdotally — associated with more physical and social disorder. Therefore, the presence of SROs may be highly correlated with a school's level of disorder, which was not measured in these studies, but may be one mechanism by which adolescents receive signals that lead to the expectation of misbehavior.

Although any of these explanations-and likely others-is possible, more research is needed to further explicate this relationship. The findings here suggest that there is a positive relationship between the presence of SROs and rates of exclusionary discipline in high school settings, but a more precise examination of the mechanisms that yielded this relationship was not possible. In the midst of a national dialog about education where exclusionary discipline has increasingly come into focus, it is critical to further examine what particular policies and actions are leading to such high rates of exclusionary discipline. This study found that the empirical research to date collectively points to the presence of SROs in high schools as one potential schoollevel factor to examine; however, it also highlights the large gap and opportunities for research in this field. Further quantitative work is needed to examine the causal relationships between SRO presence and exclusionary discipline, and further qualitative research could shed light on SROs' interactions with school discipline processes. It is unlikely that SROs will ever completely disappear from schools-there is much public and political momentum behind them, particularly as agents of promoting physical safety at school. However, it is critical to weigh the benefits of having SROs in schools against any potential negative consequences, especially those that could increase educational disparities among developing students.

\section{Limitations}

Although the results of one of the two meta-analyses achieved statistical significance and similar patterns of findings emerged across the two models, the results need to be interpreted cautiously. The nature of meta-analyses is such that the quality of results depends on the quality of research on which they are based. Unfortunately, much of 
the research on SRO effectiveness lacks the rigor necessary for drawing strong conclusions. There have not been any randomized experiments that evaluate SROs' impact on school-based discipline, crime or violence, perhaps because of the politically contentious proposition of randomly assigning some schools to receive additional school safety resources that may ease the fears of parents in the wake of school-related tragedies (Addington 2009). Additionally, none of the pre-post reports had the recommended four data points needed to establish a reliable trend over time (Bloom 2003). Therefore, the pre-post reports synthesized here are subject to threats to internal validity such as maturation or history, where any effect caused by SROs cannot be isolated from other changes in the population or context of the school. Regression to the mean is also a possible threat to validity, where schools with unusually high crime rates may have decided to hire SROs to mitigate the problems, when the passage of time would have likely brought the rate back towards the average. These limitations in the original studies limit the conclusions that can be drawn from this meta-analysis; any changes is rates of disciplinary incidents from pretest to posttest may be due to SRO presence, but also may be due to a set of other factors that were not measured or reported. Schools rarely implement only one safety- or security-related intervention (Steinka-Fry et al. under review), and the relative impact of SROs cannot be isolated from the effects of other interventions in a pre-post design.

Methodological limitations were also present in the studies that used comparison schools without SROs. For instance, schools were not matched well (e.g., only on school size), and differences between schools in terms of racial composition, average socioeconomic status, and other key demographic characteristics were not examined thoroughly. Evidence of closely matched schools is important for ruling out alternative explanations for any difference in outcomes. Non-equivalent comparison schools are less helpful for isolating the effect of SROs than schools matched well so that schools with and without SROs have comparable baseline characteristics. Therefore, the results of this meta-analysis of reports using comparison school designs must be interpreted cautiously as well. Although the overall patterns of the two meta-analyses were similar, the sample sizes (and associated statistical power) were small, increasing the likelihood that additional studies could have meaningfully affected the results. Perhaps the strongest conclusion to be drawn from the analyses, however, is that the large amount of heterogeneity in the effects detected in this study indicates that the relationship between the presence of SROs and rates of exclusionary discipline may vary significantly across contexts based on other unmeasured characteristics.
Several limitations to this review stem from a lack of consistent reporting of information in the primary studies included. For example, there was a lack of detailed data about the SROs' roles and responsibilities within schools and districts as well as the extent of SROs' involvement in any given school or district. Any effect of SROs on exclusionary discipline would likely vary depending on the number of SROs assigned to a given school or whether the SRO is part-time or full-time. Additionally, more information about schools and their contexts would be useful for gaining a more thorough understanding of the effect of SROs. For instance, information about racial composition, school climate, community crime rates, and perceptions of SROs could all affect how SROs influence school-based disciplinary incidents. Further research is needed to examine not only the overall relationship between the presence of SROs and exclusionary discipline rates, but the underlying mechanisms that drive this relationship. One choice that we made was to define exclusionary discipline as not inclusive of in-school suspensions, detentions, or other sanctions that keep students in school but may remove them from the classroom. However, SROs may also have an impact on these important outcomes of interest, and future research should examine this potential impact.

\section{Implications}

The results of this comprehensive literature search and synthesis have implications for the direction of research regarding SROs and exclusionary discipline. First, there is a pressing need to improve the methodological rigor of studies that examine this relationship. The results from this meta-analysis indicate that schools with SROs tend to have higher rates of disciplinary incidents-especially out-ofschool suspensions - than do those schools without SROs. However, this conclusion is based on results from studies with low methodological rigor and inconsistent reporting. Additionally, any true positive impact of SROs might not be in reducing rates of school-based disciplinary incidents. For example, there is evidence that SROs develop healthy and helpful relationships with adolescents in some contexts (James et al. 2011), something that improves outcomes for adolescents (Consortium on Chicago School Research 2011). However, as Kupchik (2010) argued, perhaps relying more on guidance counselors or social workers to fulfill this role would enable adolescents to develop positive relationships with adults outside of schools' formal disciplinary structure while mitigating some of the possible risks associated with SROs, such as increased exclusionary discipline.

Second, the relationship between SROs and exclusionary discipline needs to be examined in the context of adolescents' race and schools' racial composition. It was 
our original intention to examine this relationship in this study, but primary studies did not report it sufficiently. Although there is an extensive literature base that has identified racial disparities in exclusionary discipline (e.g., Hoffman 2014; Gregory et al. 2010; Skiba et al. 2014), and a largely theoretical and qualitative literature pertaining to SROs and race (e.g., Hirschfield 2008; Kupchik and Monahan 2006; Noguera 1995), there are few rigorous quantitative studies that have examined the role that race plays in the relationship between SRO presence and exclusionary discipline. One such study (Na and Gottfredson 2011) used longitudinal data from the School Survey on Crime and Safety, and found that the relationship between SRO presence and exclusionary discipline did not depend on the proportion of non-White students in a school. However, more work is needed to examine the particular mechanisms by which racial disciplinary disparities come about, particularly in regard to SROs. Further research examining the role of SROs in the discipline process is another critical next step for research, particularly in light of recent events in Ferguson, Missouri that have illuminated the tensions between police and young men of color. More information about this relationship could potentially help to explain the findings presented here and shed further light on racial disciplinary disparities.

Schools considering hiring an SRO should carefully consider the existing research and weigh the relative costs and benefits of having an SRO in the building. If they hope to reduce discipline rates, there is not compelling evidence that the presence of SROs alone will accomplish this task. Future research needs to increase the high-quality evidence base regarding the effects of SROs by conducting rigorous experiments or quasi-experiments that measure multiple outcomes relevant to school safety and discipline and consider important contextual characteristics of the schools such as racial composition. Further in-depth qualitative research could also lend insight into the mechanisms by which SROs may affect school discipline. In a political climate where the White House is prioritizing an increase in SROs' presence in schools, researchers have a unique opportunity to evaluate this effort and provide valuable information and direction as school safety policies continue to develop.

\section{Conclusion}

In an educational climate where concerns about school safety have been perpetuated by dramatic high-profile incidents of school violence such as the shootings at Columbine High School in 1999 and Sandy Hook Elementary School in 2012, SROs have become increasingly commonplace within schools nationwide. Because schools are critical sites of development for adolescents (Eccles and Roeser 2011), it is critical to understand the consequences - both intended and unintended - of the presence of SROs in schools. As such, this study provided a systematic review and synthesis of existing research on the relationship between the presence of SROs and exclusionary discipline in U.S. high schools. The findings from studies using a pre-post design indicate that schools with SROs suspend and expel adolescents at higher rates, with the presence of SROs associated with roughly one additional disciplinary incident per week in a school of 1500 students. Although it is unclear whether SROs are the mechanism driving these higher rates of discipline, the findings of this study indicate that researchers should continue to examine this relationship, particularly given the fact that receiving exclusionary discipline is associated with poorer developmental outcomes for adolescents, including lower academic achievement, dropout, and increased behavioral problems both in and out of school (Arcia 2006; Balfanz et al. 2015; Christle et al. 2005, 2007; Fabelo et al. 2011; Raffaele Mendez 2003; Suh and Suh 2007). This study highlights the importance of critically examining the roles of SROs in schools, and finding ways to align their responsibilities with strategies for fostering positive adolescent development.

Acknowledgments Thanks to Maury Nation, Emily Tanner-Smith, Mark Lipsey, and Denise Gottfredson for comments on earlier versions of this manuscript. Author BWF conceived of the study, coordinated the design, data collection, and analysis, and led in the drafting of the manuscript. Author AEH participated in data collection and analysis and helped to draft the manuscript. Both authors read and approved the final manuscript.

Conflict of interest The authors declare that they have no conflict of interest.

\section{References}

\section{References marked with an asterisk indicate studies included in the meta-analysis}

Addington, L. A. (2009). Cops and cameras: Public school security as a policy response to Columbine. American Behavioral Scientist, 52, 1426-1446. doi:10.1177/0002764209332556.

Arcia, E. (2006). Achievement and enrollment status of suspended students: Outcomes in a large, multicultural school district. Education and Urban Society, 38, 359-369. doi:10.1177/ 0013124506286947.

Balfanz, R., Byrnes, V., \& Fox, J. H. (2015). Sent home and put off track: The antecedents, disproportionalities, and consequences of being suspended in the 9th grade. In D. J. Losen (Ed.), Closing the school discipline gap: Equitable remedies for excessive exclusion (pp. 17-30). New York, NY: Teachers College Press.

*Barnes, L. M. (2008). Policing the schools: An evaluation of the North Carolina school resource officer program (Doctoral 
dissertation). Retrieved from ProQuest Dissertations and Theses. (ProQuest No. 304372953).

Bloom, H. S. (2003). Using "short" interrupted time-series analysis to measure the impacts of whole-school reforms: With applications to a study of accelerated schools. Evaluation Review, 27(3), $3-49$.

Borenstein, M., Hedges, L. V., Higgins, P. T., \& Rothstein, H. R. (2009). Introduction to meta-analysis. West Sussex: Wiley.

Borum, R., Cornell, D. G., Modzeleski, W., \& Jimerson, S. R. (2010). What can be done about school shootings? A review of the evidence. Educational Researcher, 39, 27-37. doi:10.3102/ 0013189X09357620.

Brady, K. P., Balmer, S., \& Phenix, D. (2007). School-police partnership effectiveness in urban schools: An analysis of New York City's Impact Schools Initiative. Education and Urban Society, 39, 455-478.

Brown, B. W., \& Saks, D. H. (1986). Measuring the effects of instructional time on student learning: Evidence from the Beginning Teacher Evaluation Survey. American Journal of Education, 94, 480-500.

Canady, M., James, B., \& Nease, J. (2012). To protect \& educate: The school resource officer and the prevention of violence in schools. Retrieved from http://www.nasro.org/sites/default/files/pdf_files/ NASRO_Protect_and_Educate.pdf

Christle, C. A., Jolivette, K., \& Nelson, C. M. (2005). Breaking the school to prison pipeline: Identifying school risk and protective factors for youth delinquency. Exceptionality, 13(2), 69-88.

Christle, C. A., Jolivette, K., \& Nelson, C. M. (2007). School characteristics related to high school dropout rates. Remedial and Special Education, 28, 325-339.

Clark, D., \& Linn, M. C. (2003). Designing for knowledge integration: The impact of instructional time. The Journal of the Learning Sciences, 12, 451-493.

Cohen, L. E., \& Felson, M. (1979). Social change and crime rate trends: A routine activity approach. American Sociological Review, 44, 588-608.

Consortium on Chicago School Research. (2011). Student and teacher safety in Chicago Public Schools: The roles of community context and school social organization. Retrieved from http:// ccsr.uchicago.edu/publications/student-and-teacher-safety-chicagopublic-schools-roles-community-context-and-school

Cooper, H., DeNeve, K., \& Charlton, K. (1997). Finding the missing science: the fate of studies submitted for review by a human subjects committee. Psychological Methods, 2, 447-452.

Covert, S. P. (2007). The roles and functions of school resource officers in Virginia public middle schools as perceived by Virginia middle school administrators (Doctoral dissertation). Retrieved from ProQuest Dissertations and Theses. (ProQuest No. 3288681)

Deeks, J. J., Higgins, J. P. T., \& Altman, D. G. (2008). Chapter 9: Analysing data and undertaking meta-analyses. In J. P. T Higgins \& S. Green, S. Cochrane handbook for systematic reviews of interventions. Version 5.0.1. The Cochrane Collaboration. Retrieved from http://hiv.cochrane.org/sites/hiv.cochrane.org/ files/uploads/Ch09_Analysing.pdf

Dickersin, K. (1997). How important is publication bias? AIDS Education and Prevention, 9, 15-21.

Dickmann, E. M. (1999). The culture of school resource officers: An ethnographic perspective (Doctoral dissertation). Retrieved from ProQuest Dissertations and Theses. (ProQuest No. 304498948).

Eccles, J. S., \& Roeser, R. W. (2011). Schools as developmental contexts during adolescence. Journal of Research on Adolescence, 21, 225-241. doi:10.1111/j.1532-7795.2010.00725.x.

Fabelo, T., Thompson, M. D., Plotkin, M., Carmichael, D., Marchbanks, M. P, I. I. I., \& Booth, E. A. (2011). Breaking schools' rules: A statewide study of how school discipline relates to students' success and juvenile justice involvement. New York, NY: Council of State Governments Justice Center.

Finn, P., \& McDevitt, J. (2005). National assessment of school resource officer programs final project report. Retrieved from https://www.ncjrs.gov/pdffiles1/nij/grants/209273.pdf

*Finn, P., McDevitt, J., Lassiter, W., Shively, M., \& Rich, T. (2005a). Case studies of 19 school resource officer (SRO) programs. Retrieved from https://www.ncjrs.gov/pdffiles1/nij/grants/ 209271.pdf

Finn, P., Shively, M., McDevitt, J., Lassiter, W., \& Rich, T. (2005b). Comparison of program activities and lessons learned among 19 school resource officer (SRO) programs. Retrieved from http:// files.eric.ed.gov/fulltext/ED486266.pdf

Gregory, A., Skiba, R. J., \& Noguera, P. A. (2010). The achievement gap and the discipline gap: Two sides of the same coin? Educational Researcher, 39(1), 59-68.

Hirschfield, P. J. (2008). Preparing for prison? The criminalization of school discipline in the USA. Theoretical Criminology, 12, 79-101.

Hirschfield, P. J., \& Celinska, K. (2011). Beyond Fear: Sociological Perspectives on the Criminalization of School Discipline. Sociology Compass, 5, 1-12. doi:10.1111/j.1751-9020.2010. 00342.x.

Hirschi, T. (2002). Causes of delinquency. Piscataway, NJ: Transaction Publishers.

Hirschi, T., \& Gottfredson, M. R. (2003). Punishment of children from the perspective of control theory. In C. L. Britt \& M. R. Gottfredson (Eds.), Control theories of crime and delinquency (pp. 151-160). New Brunswick, New Jersey: Transaction Publishers.

Hoffman, S. (2014). Zero benefit: Estimating the effect of zero tolerance discipline policies on racial disparities in school discipline. Educational Policy, 28, 69-95. doi:10.1177/ 0895904812453999.

James, R. K., Logan, J., \& Davis, S. A. (2011). Including School Resource Officers in school-based crisis intervention: Strengthening student support. School Psychology International, 32, 210-224.

*Johnson, I. M. (1999). School violence: The effectiveness of a school resource officer program in a Southern city. Journal of Criminal Justice, 27, 173-192. doi:10.1016/S0047-2352(98) 00049-X.

Kupchik, A. (2010). Homeroom security: School discipline in an age of fear. New York: New York University Press.

Kupchik, A., \& Monahan, T. (2006). The New American school: Preparation for post-industrial discipline. British Journal of Sociology of Education, 27, 617-631.

*Link, J. W. (2010). School resource officers in Missouri public schools: School safety and academic success (Doctoral dissertation). Retrieved from ProQuest Dissertations and Theses. (ProQuest No. 853648859).

May, D. C., Fessel, S. D., \& Means, S. (2004). Predictors of principals' perceptions of school resource officer effectiveness in Kentucky. American Journal of Criminal Justice, 29, 75-93.

Mitchell, M. M., \& Bradshaw, C. P. (2013). Examining classroom influences on student perceptions of school climate: The role of classroom management and exclusionary discipline. Journal of School Psychology, 51, 599-610. doi:10.1016/j.jsp.2013.05.005.

Mulqueen, S. (1999). School resource officers more than security guards. American School and University, 71, SS17.

Murray, B. J. (2003). Perceptions of principals, school resource officers, and school resource officer supervisors of the school resource officer program in comprehensive high schools in Riverside County, California (Doctoral dissertation). Retrieved from ProQuest Dissertations and Theses. (ProQuest No. 305272587). 
Na, C., \& Gottfredson, D. C. (2011). Police officers in schools: Effects on school crime and the processing of offending behaviors. Justice Quarterly, 30, 619-650.

Noguera, P. A. (1995). Preventing and producing violence: A critical analysis of responses to school violence. Harvard Educational Review, 65, 189-212.

Perry, B. L., \& Morris, E. W. (2014). Suspending progress: Collateral consequences of exclusionary punishment in public schools. American Sociological Review, 79, 1067-1087. doi:10.1177/ 0003122414556308 .

Petrosino, A., Guckenberg, S., \& Fronius, T. (2012). 'Policing schools' strategies: A review of the evaluation evidence. Journal of MultiDisciplinary Evaluation, 8, 80-101.

Polanin, J. R., Tanner-Smith, E. E., \& Hennessy, E. A. (2015). Estimating the difference between published and unpublished effect sizes. A meta-review. Review of Educational Research, doi: $10.3102 / 0034654315582067$.

Pittaro, M. L. (2007). School violence and social control theory: An evaluation of the Columbine massacre. International Journal of Criminal Justice Sciences, 2, 1-12.

Raffaele Mendez, L. M. (2003). Predictors of suspension and negative school outcomes: A longitudinal investigation. In J. Wald \& D. J. Losen (Eds.), New directions for youth development. San Francisco, CA: Jossey-Bass.

Raffaele Mendez, L. M., Knoff, H. M., \& Ferron, J. M. (2002). School demographic variables and out-of-school suspension rates: A quantitative and qualitative analysis of a large, ethnically diverse school district. Psychology in the Schools, 39, 259-277. doi:10. 1002/pits. 10020 .

Rausch, M. K., Skiba, R. J., \& Simmons, A. B. (2004). The academic cost of discipline: The relationship between suspension/expulsion and school achievement. Bloomington, IN: Indiana University.

*Rich-Shea, A. (2010). Adolescent youth and social control: The changing role of public schools (Doctoral dissertation). Retrieved from ProQuest Dissertations and Theses. (ProQuest No. 808531067).

Rippetoe, S. J. (2010). Teachers' and students' perceptions about the roles of school resource officers in maintaining school safety (Doctoral dissertation). Retrieved from ProQuest Dissertations and Theses. (ProQuest No. 3392118).

Robers, S., Kemp, J., Truman, J., \& Snyder, T. D. (2013). Indicators of school crime and safety: 2012. Washington, D. C.: U. S. Department of Education, National Center for Education Statistics, and Bureau of Justice Statistics, Office of Justice Programs, U. S. Department of Justice.

Rosenthal, R. (1979). The "file drawer problem" and tolerance for null results. Psychological Bulletin, 86, 638-641.

Rosenthal, R., \& DiMattateo, M. R. (2001). Meta-analysis: Recent developments in quantitative methods for literature reviews. Annual Review of Psychology, 52, 59-82.
Rothstein, H. R., Sutton, A. J., \& Borenstein, M. (2005). Publication bias in meta-analysis: Prevention, assessment and adjustments. West Sussex: Wiley.

Sampson, R. J., \& Groves, W. B. (1989). Community structure and crime: Testing social-disorganization theory. American Journal of Sociology, 94, 774-802.

Scherer, R. W., Langengberg, P., \& von Elm, E. (2007). Full publication of results initially presented in abstracts. Cochrane Database of Systematic Reviews, 2, MR000005.

Shaw, C., \& McKay, H. (1942). Juvenile delinquency and urban areas. Chicago: University of Chicago Press.

Skiba, R. J., Chung, C., Trachok, M., Baker, T. L., Sheya, A., \& Hughes, R. L. (2014). Parsing disciplinary disproportionality: Contributions of infraction, student, and school characteristics to out-of-school suspension and expulsion. American Educational Research Journal, 51, 640-670. doi:10.3102/000283124541670.

Steinka-Fry, K. T., Fisher, B. W., \& Tanner-Smith, E. E. (under review). Typologies and predictors of visible security measures across diverse middle and high school settings.

Suh, S., \& Suh, J. (2007). Risk factors and levels of risk for high school dropouts. Professional School Counseling, 10, 297-306.

The White House (2013). Now is the time: The president's plan to protect our children and communities by reducing gun violence. Retrieved from http://www.whitehouse.gov/sites/default/files/ docs/wh_now_is_the_time_full.pdf

*Theriot, M. T. (2009). School resource officers and the criminalization of student behavior. Journal of Criminal Justice, 37, 280-287.

Tobin, T., Sugai, G., \& Colvin, G. (1996). Patterns in middle school discipline records. Journal of Emotional and Behavioral Disorders, 4, 82-94.

U.S. Department of Education (2014). Guiding principles: A resource guide for improving school climate and discipline. Retrieved from http://www2.ed.gov/policy/gen/guid/school-discipline/guid ing-principles.pdf

U.S. Department of Education, Institute of Education Sciences, National Center for Education Statistics (2013). ElSi QuickFacts. Retrieved from: http://nces.ed.gov/ccd/elsi/

Valentine, J. C., Pigott, T. D., \& Rothstein, H. R. (2010). How many studies do you need? A primer on statistical power for metaanalysis. Journal of Educational and Behavioral Statistics, 35, 215-247.

*Wilkerson, D. M. H. (2001). The relationship between the school resource officer and patterns of suspensions from school due to violence, gang activity and substance/alcohol abuse (Doctoral dissertation). Retrieved from ProQuest Dissertations and Theses. (ProQuest No. 304728639). 